\title{
Psychometric Properties of a Questionnaire on Brucellosis Prevention Behaviors Based on the PRECEDE Model Among Rural Farmers and Their Family Members
}

This article was published in the following Dove Press journal:

Risk Management and Healthcare Policy

\author{
Hadi Alizadeh-Siuki ${ }^{1,2}$ \\ Hadi Tehrani ${ }^{3}$ \\ Mehdi Gholian-Aval ${ }^{3}$ \\ Hossein Ebrahimipour ${ }^{3}$ \\ Alireza Jafari ${ }^{4}$ \\ Mohammad Vahedian-Shahroodi ${ }^{3}$ \\ 'Department of Health Education and \\ Health Promotion, Student Research \\ Committee, Mashhad University of \\ Medical Sciences, Mashhad, Iran; \\ ${ }^{2}$ Department of Public Health,School of \\ Health, Torbat Heydariyeh University of \\ Medical Sciences, Torbat Heydariyeh, \\ Iran; ${ }^{3}$ Social Determinants of Health \\ Research Center, Mashhad University of \\ Medical Sciences, Mashhad, Iran; ${ }^{4}$ Social \\ Determinants of Health Research Center, \\ Gonabad University of Medical Sciences, \\ Gonabad, Iran
}

Introduction: Brucellosis is one of the most prevalent diseases in Torbate Heidarieh, Iran; it is a common disease between human and animals. The present study aimed to review the psychometric properties of a questionnaire on brucellosis prevention behaviors based on the PRECEDE model among rural farmers and their family members (PRECEDE-QBPB).

Materials and Methods: The study was a combination of qualitative and quantitative stages. In the qualitative stage, an 86-item questionnaire including interviews with 30 farmers, their family members and other effective people, as well as literature review, was designed. In the quantitative stage, psychometric properties of the PRECEDE-QBPB including the face, content, and constructs validities, as well as reliability measurement of the questionnaire were evaluated. Item impact, content validity ratio (CVR) and content validity index (CVI) for all items were calculated. Besides, confirmatory factor analysis (CFA) was done to evaluate the construct's validity; AMOS 20 was used for this purpose. In this stage, a cross-sectional study was conducted on 500 rural farmers and their family members. To estimate the internal consistency of this questionnaire, Cronbach's alpha was used for each variable. Further, descriptive statistics and Kaiser-Meyer-Olkin and Bartlett's test of sphericity were used to describe the characteristics of the participants and collect samples, respectively.

Results: Based on the results of face validity and content validity (CVR, CVI and CFA 9), 19 and 22 items were removed, respectively, leaving the final questionnaire with 36 items and eight subscales including knowledge, attitude, self-efficacy, social support, enabling factors, environmental factors, behavioral factors, and reinforcing factors. The Cronbach's coefficient alpha was calculated for the total questionnaire $(\alpha=0.92,0.69-0.87$ for subscales). The evaluation of model fit indices showed that all indices confirmed the suitability of the final model fit; therefore, the questionnaire has suitable construct validity.

Conclusion: A questionnaire, as a valid tool, was designed in the present study. Healthcare providers, policymakers, planners, researchers may use this tool to find a comprehensive understanding of enabling, reinforcing, environmental and behavioral factors that affect brucellosis before implementing health education and health promotion programs.

Keywords: behaviors, brucellosis, questionnaire, validation, PRECEDE

\section{Introduction}

Brucellosis is one of the most contagious diseases common in animals and humans and an important health problem across the world, especially in developing countries and Iran. ${ }^{1-3}$ It is known as wavy fever, Mediterranean fever and thousand-face
Correspondence: Mohammad VahedianShahroodi

Social Determinants of Health Research

Center, Mashhad University of Medical

Sciences, Mashhad, Iran

Tel +985 I 38546634

Fax+985 138522775

Email vahedianm@mums.ac.ir 
disease due to its side-effects. Concerning the undesired health and economic consequences of brucellosis, this disease is covered by the healthcare system in most countries. ${ }^{4,5}$ Despite the developments in medicine, it has been, a health issue around the world. ${ }^{6}$ Brucellosis occurs due to consuming unpasteurized dairy products, direct contact with the polluted animal or their placenta and fetus. $^{7}$

The complications resulting from Brucellosis included great economic losses, ${ }^{6,8}$ disability, physical, mental and psychological problems, endocarditis, vertebral problem, osteomyelitis, surgical interventions, a shortage of animal and dairy production, as well as abortion, infertility, sterility in livestock. ${ }^{9-11}$ Although Brucellosis has been controlled in most developed countries, it is principally originated from some parts of the world including Latin America, Spain, parts of Africa, West Asia and the Mediterranean countries such as Turkey and Iran, and the Saudi Arabian Peninsula. Despite having the proper healthcare system in Iran, it is an endemic disease Iran is the fourth brucellosis-infected country in the world and the first in the Mediterranean. ${ }^{12,13}$

According to the World Health Organization (WHO) report, a total of 500,000 people have brucellosis annually though the mortality rate is higher than what is reported. Based on the estimations, there are 12 asymptomatic patients for each patient with clinical symptoms. ${ }^{8,14,15}$ This disease causes economic damages to the husbandry industry and human labor because of physical complications and treatment costs. ${ }^{16}$ The researchers have estimated that the treatment costs about 1000 dollars. ${ }^{7}$ This disease has an ascending trend in Iran up to 1989 and, descending trend until 2004; then it raised to 500 of 100,000 people. ${ }^{17}$

To modify health-related behaviors, various studies have been conducted in Iran. They are centered on educational interventions on an infectious disease such as brucellosis. ${ }^{18-20}$ Furthermore, various studies showed that the control of brucellosis requires integrated and collaborative actions from both human and animal health sectors as well as political support and consultation from other sectors or related organizations, especially on a regional scale. Thus, tackling this problem requires highlevel advocacy. ${ }^{21-23}$ Moreover, it is necessary to recognize all effective important factors affecting on the brucellosis incidence. To clarify these factors, the PRECEDE model was used as a framework and planning model. According to Green and Kreuter, to correct behaviors, not only an individual but also the environment surrounding him should be considered. ${ }^{24}$ This model consists of several constructs including procedural constructs such as behavioral, environmental, educational, ecological, organizational, and social assessments. The educational and ecological assessments consist of three factors including predisposing factors, enabling factors and reinforcing factors. $^{25}$

Predisposing factors provide motivation and the main reasons for performing health behaviors. These factors were employed to assess the knowledge, attitude, and self-efficacy of the individuals concerning preventive behaviors. Reinforcing factors measure the role of social and family support in brucellosis-preventive behaviors. Enabling factors to measure the extent of availability of the resources and facilities required to facilitate preventive behaviors.

In Torbat-e Heydarieh, Khorasan-e Razavi Province, the incidence of disease has shown an ascending trend since 2011, which is much greater (21 cases per 100,000 individuals) than the average estimate of the country. ${ }^{26}$ Considering the reason for the high prevalence of brucellosis in Torbate Heydarieh, the strategies used to reduce the morbidity of brucellosis and the lack of a measurable standard tool to design a comprehensive brucellosis prevention plan, the researchers tried to design a comprehensive plan with the PRECEDE model. Thus, the present study aimed to design and evaluate the psychometric properties of the questionnaire based on the PRECEDE model among farmers and their families in the rural population.

\section{Materials and Methods}

This study was conducted in both qualitative (design and development) and the quantitative stages (the assessment of psychometric properties of the instrument).

\section{Qualitative Stage (Design and Development of Instrument)}

In the first stage, the qualitative content analysis was done in villages with a high prevalence of brucellosis (based on the statistics and documents of province health center), some farmers were interviewed and other interviews were conducted with the snowballing method. In sum, 30 interviews ( 3 physicians, 8 farmers, 5 family members, 1 veterinarian, 4 health experts, 3 healthcare providers, 1 governor of the village, 1 council members, 2 healthy 
volunteers, 1 butcher, and 1 shepherd) were conducted until the saturation of sample. The purpose of this stage was to identify behavioral and non-behavioral factors affecting the incidence of brucellosis and design the initial draft of the questionnaire based on the PRECEDE model.

A semi-structured guide questionnaire consisted of the following open-ended questions: 1) What do you know about brucellosis? Can you explain it? 2) Have you ever met aborted livestock? What have you done? 3) What do you think of the individuals and organizations which can play a part in preventing brucellosis in your village?

Then, a series of exploration questions (ie "Can you explain more or give an example") was asked to encourage participants and obtain more comprehensive information. Interviews were entered into Max QDA 2010 \and data were analyzed and categorized using Smiths' coding method. ${ }^{27}$ The resources of reviewing comprehensive data included PubMed, Google scholar, Science direct and some Persian databases such as Scientific database (SID) and Magian. Some of the keywords used for the search were including brucellosis, validity, farmer, questionnaire, and psychometric. Finally, the extracted codes were used to design the instrument.

\section{Design and Item Generation} Instruments

The questionnaire used in this study consists of demographic sections and brucellosis prevention behaviors based on the PRECEDE-model.

\section{Demographic Section}

This section includes questions on age, gender, marital status, education level, keeping the place of live stocks, and family history of brucellosis, and occupation.

\section{Brucellosis Prevention Behaviors Based on the PRECEDE- Model}

Eighty-six items were generated based on conducted interviews and surveys. We grouped these items subsequently into the eight subscales including knowledge (15 items), attitude (13 items) self-efficacy (6 items) enabling factors (7 items), reinforcing factors (11 items), social support (10 items), environmental factors (7 items) behavioral factors (17 items) based on the PRECEDE model.

We developed the knowledge construct to measure the knowledge of participants toward the cause of brucellosis, transmission and prevention methods, symptoms and preventive behaviors. The knowledge construct was measured based on 3-point responses (Yes=3, I do not know $=2$, $\mathrm{No}=1$ ). The attitude construct was developed to assess the positive and negative attitudes of participants to the disease, and measured based on a 3-point Likert scale (Agree $=3$, No idea $=2$, Disagree $=1$ ). In environmental construct, the participants were asked about the status of stable (light, ventilation, place of livestock feed) and the geographical zone. The construct of environmental factors was measured based on a 3-point Likert scale (Yes $=3$, somewhat $=2, \mathrm{No}=1$ ).

The self-efficacy construct has investigated the judgment of participants about their abilities to treat brucellosis preventing behaviors. In the construct of enabling factors, the participants were asked about the accessibility of resources to preventive behaviors of brucellosis. In the construct of reinforcing factors, the participants were asked about the extent of family, health staff and friends' supports, to do brucellosis preventive behaviors. Furthermore, another construct known as social support measured the extent of organizational and managerial supports to brucellosis preventive behaviors. In the behavioral construct, the participants were asked about brucellosis prevention behaviors such as the consumption of colostrum, the use of personal protective equipment, and boiling milk.

The constructs of self-efficacy, enabling factors, reinforcing factors, social support, and behavioral factors were measured based on a 5-point Likert scale (Always $=5$, Most often $=4$, Sometimes $=3$, Rarely $=2$, Never $=1$ ).

\section{Quantitative Stage (Assessment Psychometric Properties of the Instrument)}

This stage evaluates the psychometric properties of the PRECEDE-QBPB including the face, content, and construct validities as well as reliability measurement of the questionnaire.

\section{Face Validity}

Face validity was conducted on 10 farmers using qualitative and quantitative stages. In the qualitative stage, face-to-face interviews were conducted to evaluate difficulty and ambiguity level of items. Some items were modified based on the farmers' viewpoints. In the quantitative stage, we asked them to examine the importance of each item based on a 5-point Likert scale (Completely important $=5$, Important $=4$, Relatively important $=3$, slightly important $=2$, No impor$\tan =1)$. Then, for each item, the effect of the score was calculated based on the following formula. The items with 
an impact score of more than 1.5 were preserved for the next analysis. $^{29}$

Item Impact $=$ Frequency in percentage $\times$ Importance

\section{Content Validity}

To determine content validity, both qualitative and quantitative methods were used. In the qualitative phase, a panel of experts including 11 specialists (7 health educators, infectious diseases specialist, an epidemiologist and two specialists of educational nursing) According to their views, wording, proportionality and scaling of items were modified. Moreover, the content validity index (CVI) and content validity ratio (CVR) were used for quantitative evaluation. ${ }^{30}$

To determine the content validity rate, the above-mentioned specialists were asked to express their views using three words of necessary, useful but unnecessary, unnecessary. Further, to determine the content validity index of each item, three criteria of simplicity, relevance and clarity were measured by the 4-point Likert scale. For simplicity, the items were extremely simple, simple, relatively simple and not simple; for relevance, the items were completely relevant, relevant, slightly relevant, and not relevant; for the clarity, three items of completely clear, clear, slightly clear and non-clear were used. ${ }^{31}$ CVR and CVI were calculated through the following formulas:

$$
C V R=\frac{n_{E}-(N / 2)}{N / 2}
$$

In this formula, $N_{E}$ is the number of experts chosen optionally (it is necessary) and $\mathrm{N}$ is the number of whole experts.

$$
\mathrm{CVI}=\frac{\text { Number of raters chosing points } 3 \text { and } 4}{\text { Total number of raters }}
$$

Based on the Lawshe's quantitative approach to CVR and the number of the specialists $(n=11)$, the minimum value determined for the content validity ratio and content validity index was 0.59 and 0.79 , respectively. ${ }^{28}$

\section{Construct Validity Assessment}

Construct validity was evaluated through confirmatory factor analysis (CFA). In this stage, a cross-sectional study was conducted on 500 subjects from 4 rural regions of Torbat Heydariyeh, Khorasan Razavi province, Iran.

\section{Sampling Method}

Data were collected using stratified random sampling. At first, Torbat Heydariyeh was divided into four clusters and three health centers from each cluster were randomly selected. Then, the health center of each village and samples were selected randomly concerning the record of the household's health. Further, the purpose of the study was explained to the households and self- administrated-questionnaires were completed.

In the present study, inclusion criteria included 18-60 years of age one-year residency in the village, completion of written consent of, having a medical record in the health center of the village; and those who were illiterate or not willing to interview were excluded from the study. It is worth noting that family members who met the inclusion criteria included in the study.

For confirmatory factor analysis, AMOS 20 was used. The model was evaluated using the following indices: chisquare indicators $(\mathrm{x} 2)$, chi-square ratio to the degree of freedom (x2/df), root-mean-square error of approximation (RMSEA), adjusted goodness of fit index (AGFI); parsimony comparative fit index (PCFI), comparative fit index (CFI); incremental fit index (IFI) and parsimonious normed fit index (PNFI). ${ }^{29-31}$ The model was considered to be a good fit if the $(\mathrm{x} 2 / \mathrm{df})<5, \mathrm{RMSEA} \leq 0.08, \mathrm{AGFI}>$ $0.8, \mathrm{PCFI}$ and $\mathrm{PNFI}>0.5, \mathrm{CFI}$ and $\mathrm{IFI}>0.9 .^{29-32}$

Table I Frequency Distribution of Demographic and Other

\begin{tabular}{|c|c|c|c|}
\hline Variables & & $\mathbf{N}$ & $\%$ \\
\hline Gender & $\begin{array}{l}\text { Male } \\
\text { Female }\end{array}$ & $\begin{array}{l}271 \\
229\end{array}$ & $\begin{array}{l}54.2 \\
45.8\end{array}$ \\
\hline Marital status & $\begin{array}{l}\text { Marriage } \\
\text { Single }\end{array}$ & $\begin{array}{l}448 \\
52\end{array}$ & $\begin{array}{l}89.6 \\
10.4\end{array}$ \\
\hline Education level & $\begin{array}{l}\text { Literacy for reading and } \\
\text { writing } \\
\text { Primary school } \\
\text { High School } \\
\text { Academic }\end{array}$ & $\begin{array}{l}84 \\
216 \\
165 \\
35\end{array}$ & $\begin{array}{l}16.8 \\
43.2 \\
33 \\
7\end{array}$ \\
\hline $\begin{array}{l}\text { Do you have cows, sheep } \\
\text { or goats? }\end{array}$ & $\begin{array}{l}\text { Yes } \\
\text { No }\end{array}$ & $\begin{array}{l}489 \\
11\end{array}$ & $\begin{array}{l}97.8 \\
2.2\end{array}$ \\
\hline $\begin{array}{l}\text { Where are your livestock } \\
\text { kept? }\end{array}$ & $\begin{array}{l}\text { Inside the house } \\
\text { Outside the house }\end{array}$ & $\begin{array}{l}263 \\
237\end{array}$ & $\begin{array}{l}52.6 \\
47.4\end{array}$ \\
\hline $\begin{array}{l}\text { What is your dairy } \\
\text { consumption? }\end{array}$ & $\begin{array}{l}\text { local } \\
\text { Pasteurized }\end{array}$ & $\begin{array}{l}425 \\
75\end{array}$ & $\begin{array}{l}85.9 \\
14.1\end{array}$ \\
\hline $\begin{array}{l}\text { Family history of having } \\
\text { brucellosis }\end{array}$ & $\begin{array}{l}\text { Yes } \\
\text { No }\end{array}$ & $\begin{array}{l}122 \\
378\end{array}$ & $\begin{array}{l}24.6 \\
76.4\end{array}$ \\
\hline Season of prevalence & $\begin{array}{l}\text { Spring } \\
\text { Sumer } \\
\text { Autumn } \\
\text { Winter }\end{array}$ & $\begin{array}{l}320 \\
132 \\
12 \\
36\end{array}$ & $\begin{array}{l}64 \\
26.4 \\
2.4 \\
7.2\end{array}$ \\
\hline
\end{tabular}
Factors of Understudied Population 
Table 2 Cronbach's Alpha and CVR and CVI Constructs

\begin{tabular}{|l|l|l|l|l|}
\hline Variables & Items & Cronbach's Alpha & CVR & CVI \\
\hline Knowledge & 4 & 0.79 & 0.77 & 0.82 \\
Attitude & 4 & $08 I$ & 0.78 & 0.72 \\
Self-efficacy & 3 & 0.70 & 0.76 & 0.8 \\
Social support & 4 & 0.74 & 0.68 & 0.95 \\
Enabling factors & 3 & 0.69 & 0.78 & 0.81 \\
Behavioral factors & 8 & 0.87 & 0.87 & 0.72 \\
Environmental factors & 3 & 0.77 & 0.71 & 0.81 \\
Reinforcing factors & 7 & 0.86 & 0.77 & 0.88 \\
\hline
\end{tabular}

\section{Statistical Analysis}

In the present study, different tools were used for the statistical analysis. They include SPSS 20 (To summarize and organize the data), Analysis of Moment Constructs (AMOS) v.10 (To conduct confirmatory factor analysis (CFA)), The Kolmogorov-Smirnov (K-S) test (To evaluate the data normal distribution), Cronbach alpha (To estimate the internal consistency of this questionnaire), KaiserMeyer-Olkin (KMO) and Bartlett's test of sphericity (To get sufficient samples). Besides, descriptive statistics were used to describe the characteristics of the participants.

\section{Ethical Considerations}

This study was conducted under the Declaration of Helsinki and approved by the Ethics Committee of Mashhad
University of Medical Sciences (with the code of ethics: IR.MUMS.REC.1397.142). First, the aims of the study were explained to the participants and their written informed consent obtained and approved by Mashhad University of Medical Sciences. All participants were insured that their information will be kept confidential.

\section{Result}

The results of the study are presented in two parts including qualitative stage (design and development of the instrument) and quantitative stage (the evaluation of the psychometric properties PRECEDE-QBPB). To evaluate construct validity, a cross-section study was conducted on 500 subjects. The mean (SD) age of the subjects was $39.02 \pm 16.41$ of whom $53.1 \%$ and $46.9 \%$ were male and female, respectively. Further, $6.9 \%$ of the samples had university degrees (Table 1).

\section{Qualitative Stage}

In this stage which is based on the conducted interviews and literature review, we demonstrated important factors affecting the brucellosis incidence. They included behavioral factors, environmental factors, the effective factors on the adoption of the behavior (predisposing, enabling and reinforcing factors). Based on the results of the qualitative study, an 86-item primary pool was formed. The

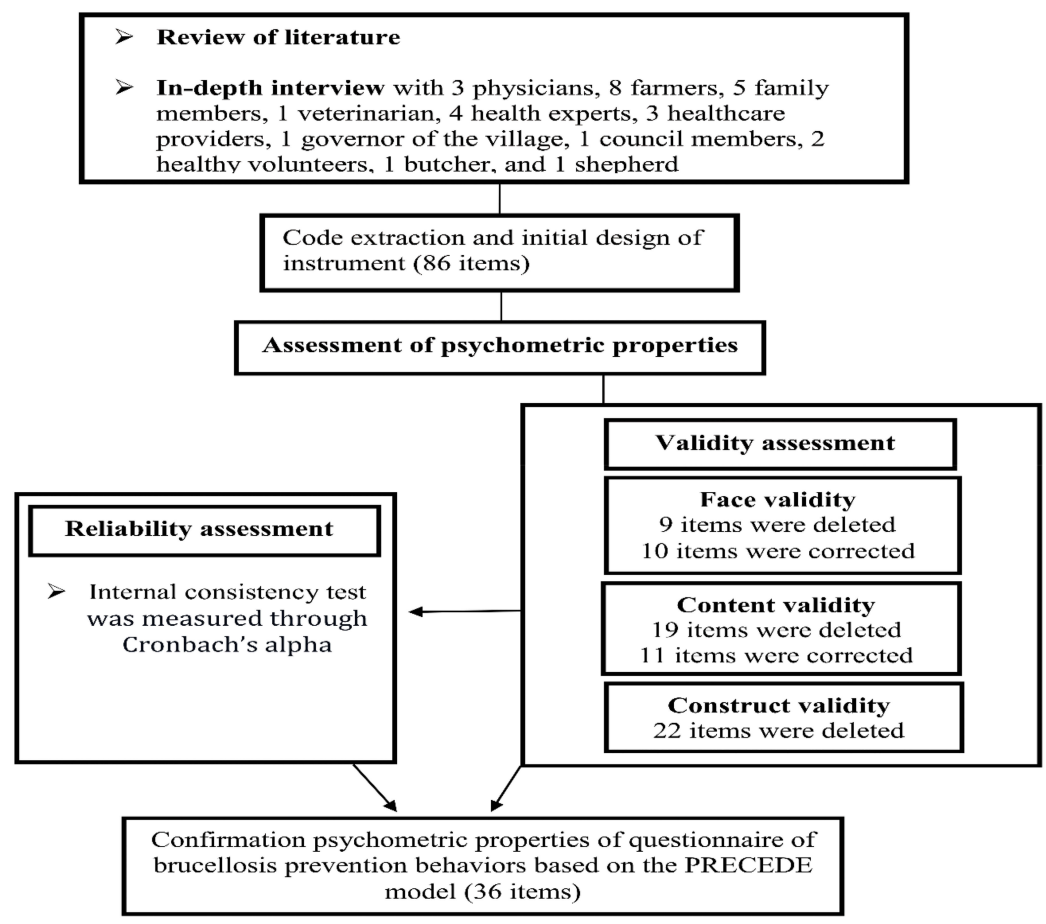

Figure I Schematic process of the reduction of the items. 
Table 3 CVR, CVI, Impact score and Factor loading of the PRECEDE-QBPB

\begin{tabular}{|c|c|c|c|c|c|c|}
\hline \multicolumn{2}{|l|}{ Variables } & Items & CVR & CVI & $\begin{array}{l}\text { Impact } \\
\text { Score }\end{array}$ & $\begin{array}{l}\text { Factor } \\
\text { Loading }\end{array}$ \\
\hline \multirow{12}{*}{$\begin{array}{l}\text { Predisposing } \\
\text { factors }\end{array}$} & \multirow[t]{4}{*}{ Knowledge } & Brucellosis transfers through respiration. & 0.8 & 0.81 & 2.73 & 0.547 \\
\hline & & Raw and half-cooked meat can be effective in transferring brucellosis. & 0.8 & 0.83 & 4.4 & 0.520 \\
\hline & & Muscle pain and night sweating are symptoms of brucellosis. & 0.79 & 0.84 & 3 & 0.648 \\
\hline & & Touching aborted cattle fetuses can lead to brucellosis in humans. & 0.8 & 0.79 & 2.1 & 0.535 \\
\hline & \multirow[t]{5}{*}{ Attitude } & Boiling milk spoils its usefulness. & 0.8 & 0.81 & 4.1 & 0.353 \\
\hline & & I use Falleh (a local food prepared by mixing not-boiled milk and & I & 0.79 & 3.2 & 0.482 \\
\hline & & colostrum) because it is delicious and useful. & & & & \\
\hline & & I think sheep do not need vaccination. & 0.82 & 0.84 & 2.8 & 0.734 \\
\hline & & The delicious taste of local cheese overweighs its risks. & 0.81 & 0.84 & 2.5 & 0.760 \\
\hline & \multirow{3}{*}{$\begin{array}{l}\text { Self- } \\
\text { efficacy }\end{array}$} & I can use gloves when working in the barn. & 0.7 & 0.8 & 2.9 & 0.652 \\
\hline & & I vaccinate my sheep on-time even if it has a high cost. & 0.78 & 0.85 & 3.2 & 0.650 \\
\hline & & I can avoid fresh local cheese even if it is delicious. & 0.8 & 0.8 & 2.9 & 0.405 \\
\hline \multirow{7}{*}{\multicolumn{2}{|c|}{ Reinforcement factors }} & $\begin{array}{l}\text { If I wore gloves during milking the cattle, my family members will } \\
\text { encourage me. }\end{array}$ & 0.72 & 0.79 & 4.1 & 0.661 \\
\hline & & $\begin{array}{l}\text { Health workers encourage me to consume milk and pasteurized dairy } \\
\text { products. }\end{array}$ & 0.85 & 0.81 & 2.2 & 0.637 \\
\hline & & $\begin{array}{l}\text { If I do not use mask and glove during cleaning the barn, healthcare } \\
\text { provider warns me about its risks. }\end{array}$ & 0.8 & 0.79 & 2.9 & 0.740 \\
\hline & & $\begin{array}{l}\text { If I use non-pasteurized and unhealthy dairy products, healthcare } \\
\text { providers object to me. }\end{array}$ & 0.75 & 0.8 & 1.57 & 0.671 \\
\hline & & My family encourages me to use a glove when slaughtering the cattle. & 0.87 & 0.81 & 2.9 & 0.724 \\
\hline & & $\begin{array}{l}\text { If I do brucellosis preventive behaviors, healthcare providers and trustees } \\
\text { in the village encourage me. }\end{array}$ & 0.83 & 0.79 & 3.6 & 0.750 \\
\hline & & $\begin{array}{l}\text { If I do not use health principles in building the barn, the healthcare } \\
\text { provider/village governor introduces me to the legal authorities. }\end{array}$ & 0.71 & 0.0 .79 & 3.4 & 0.670 \\
\hline \multirow{3}{*}{\multicolumn{2}{|c|}{ Environmental factors }} & Is the place of disposing of animal waste far from the village? & 0.75 & 0.8 & 3.2 & 0.510 \\
\hline & & Is your barn old and worn and needs restructuring? & 0.84 & 0.79 & 2.4 & 0.741 \\
\hline & & Is there a standard trough and stall for cattle in your barn? & 0.8 & 0.8 & 2.9 & 0.827 \\
\hline \multirow{4}{*}{\multicolumn{2}{|c|}{ Social support }} & Are required facilities provided by the related organizations for you? & 0.7 & 0.86 & 1.7 & 0.636 \\
\hline & & $\begin{array}{l}\text { Is there interesting educational material and film about brucellosis } \\
\text { provided by the health center? }\end{array}$ & 0.62 & 0.85 & 4.5 & 0.616 \\
\hline & & $\begin{array}{l}\text { Is taking blood sample and brucellosis test by veterinarian done to detect } \\
\text { the infected cattle? }\end{array}$ & 0.7 & 0.82 & 2.8 & 0.600 \\
\hline & & $\begin{array}{l}\text { Does the veterinary office follow and support the on-time vaccination of } \\
\text { cattle? }\end{array}$ & 0.07 & 0.9 & 4.6 & 0.697 \\
\hline \multirow{3}{*}{\multicolumn{2}{|c|}{ Enabling factors }} & $\begin{array}{l}\text { I have access to individual protective devices (masks and gloves) in my } \\
\text { living place. }\end{array}$ & 0.87 & 0.8 & 4.4 & 0.716 \\
\hline & & $\begin{array}{l}\text { I have access to disinfecting materials to cleanse the barn in my living } \\
\text { place. }\end{array}$ & 0.81 & 0.81 & 2.8 & 0.745 \\
\hline & & I have provided access to cattle vaccination services. & 0.79 & 0.85 & 3.7 & 0.711 \\
\hline \multirow{8}{*}{\multicolumn{2}{|c|}{ Behavioral factors }} & I use a mask when entering the barn. & 0.8 & 0.8 & 2.9 & 0.743 \\
\hline & & I place local cheese in saline water at least for 2 months. & 0.89 & 0.9 & 2.07 & 0.577 \\
\hline & & I vaccinate my cattle on time. & 0.78 & 0.85 & 3.2 & 0.679 \\
\hline & & In the case of cattle abortion, I inform the veterinarian's office & 0.68 & 0.81 & 3.2 & 0.576 \\
\hline & & I use a glove to chop the meat. & 0.6 & 0.79 & 3.4 & 0.734 \\
\hline & & In the case of abortion, I bury it with observing hygiene guides. & 0.8 & 0.82 & 3.7 & 0.610 \\
\hline & & I use masking and gloves during cleansing the barn. & 0.84 & 0.85 & 4.3 & 0.748 \\
\hline & & I consume colostrum of sheep. & 0.74 & 0.9 & 2.9 & 0.718 \\
\hline
\end{tabular}


items were investigated by the research team based on mutual agreement, overlapping and duplicative items were removed. In this stage, the draft of the initial PRECEDE-QBPB with 86 items was provided.

\section{Quantitative Stage}

In this stage, PRECEDE-QBPB was evaluated based on the face, content, and construct validities as well as reliability.

\section{Face Validity}

In the qualitative face validity assessment, 10 items were modified according to the farmers' opinion and 9 items were omitted during the face validity assessment. Finally, 77 items entered the next stage (Table 2, Figure 1).

\section{Content Validity}

Base on the feedback from the panel of specialists, 11 items were modified and 19 items were omitted. In quantitative content validity assessment, CVR and CVI were calculated and 10 and 9 items were omitted, respectively (Table 2, Figure 1).

\section{Construct Validity}

The Kaiser-Meyer-Olkin test statistic (0.87) revealed that the sampling adequacy for CFA and Bartlett's septicity test was significant $(\mathrm{p}<0.001)$. Based on CFA results, 22 items with a regression coefficient $(\geq 0.30)^{33}$ were excluded from the questionnaire. Table 3 and Figure 2 display the lodging value of each question. The goodness of fit for the measurement of CFA was acceptable. $(\mathrm{X} 2 / \mathrm{df}=2.91$, RMSEA $=0.04, \mathrm{AGFI}=0.80, \mathrm{GFI}=0.91, \mathrm{PNFI}=0.70, \mathrm{PCFI}=$ 0.75 ) (Table 4). The final version of questionnaire included a total of 36 items consisting of knowledge (4 items), attitude (4 items), self-efficacy (3 items), enabling factors (3 items), reinforcing factors ( 7 items), social support (4 items), environmental factors (3 items), and behavioral factors ( 8 items)

\section{Reliability}

To ensure PRECEDE-QBPB's internal consistency, Cronbach's alpha was measured for each variable. The alpha rate for behavioral factor and reinforcing factor was 0.87 and 0.86 , respectively (Table 2 ).

\section{Discussion}

The present study was conducted to develop and psychometric analysis of an instrument to promote brucellosis preventive behaviors among rural farmers and their families based on the PRECEDE model. This model was

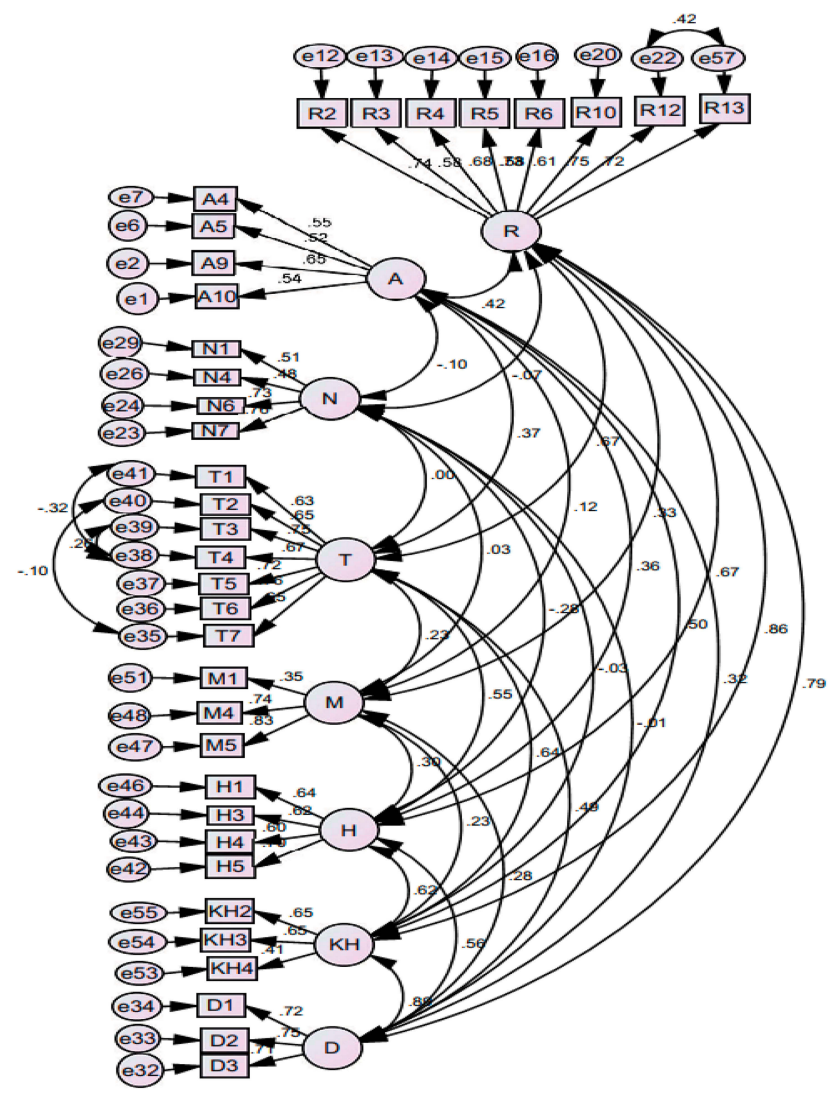

Figure 2 CFA-based relations between the items and the constructs. Abbreviations: $A$, knowledge; $N$, attitude; $T$, reinforcing factor; $M$, environment; $\mathrm{H}$, social support; $\mathrm{KH}$, self-efficacy; $\mathrm{D}$, enabling factor.

developed by the interview and using expert opinions, and continued by deleting items, testing them and revising the scale. The present study was performed on a large scale of samples. The results of this study showed the reliability and validity of the questionnaire.

In the first phase of this study (qualitative phase), an 86-item tool was designed through expert panel (face and content validity) and reduced to 36 items with confirmatory factor analysis. In the study of Ahmadzadeh et.al, ${ }^{34}$ 56 items were designed and only 26 items were selected by expert opinions. Finally, the number of items reduced to 17 by factor analysis.

The results of reliability and validity indicate the proper psychometric features for the designed tool. Polit ${ }^{35}$ believes that the validity of the questionnaire is one of the most important indices used to convince the target group to participate in the test. This can also impact the results of the test.

Further, He states that content validity is necessary to measure the questionnaire. He argues that although there is no integrated method for content analysis, using expert 
Table 4 Goodness-of-fit indices for the Model Proposed

\begin{tabular}{|l|l|l|l|l|l|l|l|l|l|l|}
\hline Goodness of Fit Indices & $\mathbf{X}^{\mathbf{2}}$ & $\mathbf{d f}$ & $\mathbf{X}^{\mathbf{2}}$ /df & CFI & AGFI & RMSEA & PNFI & PCFI & IFI & P-value \\
\hline Confirmatory factor analysis & 1640.400 & 562 & 2.919 & 0.901 & 0.805 & 0.062 & 0.700 & 0.754 & 0.901 & P $<0.001$ \\
\hline
\end{tabular}

opinions, as a rule, is necessary. In the present study, the content validity of the questionnaire was measured in two steps measuring CVI and CVR. Those values lower than 0.62 and 0.79 were deleted for CVR and CVI, respectively.

The validity of the questionnaire constructs was evaluated using confirmatory factor analysis. The results indicated a good fit of the model. Moreover, high factor loading was statistically significant which is consistent with the results of Mahdavi $^{33}$ Shaghaghi $^{36}$ and Gorzka's ${ }^{37}$ studies.

The results of Cronbach's alpha showed that the designed questionnaire had high internal consistency (0.92). This means that this item has required consistency. In addition, the Cronbach alpha coefficient was $0.70-0.87$ for each construct in the questionnaire. According to Polit's study, ${ }^{35}$ items with CVI more than 0.78 have good content validity. Thus, each measured item has a similar structure. Consistent with these results, Cronbach alpha for RECEDE-MSBP on 420 farmers was 0.91 and for its constructs was in the range of $0.44-0.90$. In other studies, Cronbach alpha has been used to prove the internal consistency of the tool. ${ }^{38-40}$

In this study, to investigate the relationship between behavior, enabling and reinforcing factors, the Pearson correlation test was used, indicating a significant relationship between behavior and these factors $(\mathrm{P}<0.001)$. In the study of Mahdavi et.al, ${ }^{33}$ there was a significant relationship between brucellosis preventive behaviors, enabling and reinforcing factors and self-efficacy. Consequently, social, organizational and family support of farmers and their family members can have a considerable effect on the increase of brucellosis preventive behaviors.

\section{Limitations of the Research}

One of the limitations of this study was the high level of dispersion of the villages studied and low level of literacy among some of the participants. So, completing the questionnaires was highly time-consuming.

\section{Conclusion}

In this study, a questionnaire, as a valid and reliable instrument, was designed. Health-care providers, policymakers, planners, and researchers may use this instrument to understand enabling, reinforcing environmental and behavioral factors affecting Brucellosis before the implementation of health education and health promotion programs. However, further studies should be done to compare the various aspects of PRECEDE-QBPB in various communities.

\section{Acknowledgments}

This article is part of the Ph.D. thesis in the field of health education and health promotion Sponsored by the Mashhad University of Medical Science. The authors of the study express their sincere gratitude to all authorities of Mashhad University of Medical Sciences, Deputy of Health Torbat Heydarieh University of Medical Sciences and all the persons who helped us in conducting this research.

\section{Disclosure}

No potential conflict of interest was reported by the authors.

\section{References}

1. Dobrean V, Opris A, Daraban S. An epidemiological and surveillance overview of brucellosis in Romania. Vet Microbiol. 2002;90(1-4):157163. doi:10.1016/S0378-1135(02)00251-1

2. SHoraka HMHH, Sofizadeh A, Avaznia A, Rajabzadeh R, Hwajzi A. Evaluate of the epidemiology of brucellosis in the city maneh Samalgan, North Khorasan. North Khorasan. 2010;3(2):65-72.

3. Dean AS, Crump L, Greter H, Schelling E, Zinsstag J. Global burden of human brucellosis: a systematic review of disease frequency. PLoS Negl Trop Dis. 2012;6(10):e1865. doi:10.1371/journal.pntd.0001865

4. Franc K, Krecek R, Häsler B, Arenas-Gamboa A. Brucellosis remains a neglected disease in the developing world: a call for interdisciplinary action. BMC Public Health. 2018;18(1):125. doi:10.1186/s12889-0175016-y

5. Musallam II, Abo-Shehada MN, Guitian J. Knowledge, attitudes, and practices associated with brucellosis in livestock owners in Jordan. Am J Trop Med Hyg. 2015;93(6):1148-1155. doi:10.4269/ajtmh.15-0294

6. Awah-Ndukum J, Mouiche MMM, Kouonmo-Ngnoyum L, et al. Seroprevalence and risk factors of brucellosis among slaughtered indigenous cattle, abattoir personnel and pregnant women in Ngaoundéré, Cameroon. BMC Infect Dis. 2018;18(1):611.

7. Zeng H, Wang Y, Sun X, et al. Status and influencing factors of farmers' private investment in the prevention and control of sheep brucellosis in China: a cross-sectional study. PLoS Negl Trop Dis. 2019;13(3):e0007285.

8. Golshani M, Buozari S. A review of Brucellosis in Iran: epidemiology, risk factors, diagnosis, control, and prevention. Iran Biomed J. 2017;21(6):349. 
9. Díez JG, Coelho A. An evaluation of cattle farmers' knowledge of bovine brucellosis in northeast Portugal. $J$ Infect Public Health. 2013;6(5):363-369.

10. Assenga JA, Matemba LE, Malakalinga JJ, Muller SK, Kazwala RR. Quantitative analysis of risk factors associated with brucellosis in livestock in the Katavi-Rukwa ecosystem, Tanzania. Trop Anim Health Prod. 2016;48(2):303-309. doi:10.1007/s11250-015-0951-z

11. Ayoola MC, Akinseye VO, Cadmus E, et al. Prevalence of bovine brucellosis in slaughtered cattle and barriers to better protection of abattoir workers in Ibadan, South-Western Nigeria. Pan Afr Med J. 2017;28(1). doi:10.11604/pamj.2017.28.68.10925.

12. Saeedinejad S, Mirzaee M, Parisaee Z, Khalili A, Paymard A. Prevalence of brucellosis in Kohgiluyeh and Boyer Ahmad Province in 2017. Electron J Gen Med. 2018;15(3).

13. Hosseini SM, Amani R, Razavi SV, Moshrefi A, Aghajanikhah MH, Mamoodi A. Epidemiology of Brucellosis in Amol City from 2011 to 2013. 2016:1-7.

14. Rahmanian V, Rahmanian K, Mansoorian E, Jahromi AS, Madani A. Epidemiological characteristics and temporal trend of human and bovine brucellosis cases, Southern Iran, 2009-2016. Pak J Med Health Sci. 2018;12(1):488-495.

15. Eskandari Z, Bashirian S, Barati M, Soltanian AR, Hazavehi SMM. The effect of educational program based on the health belief model on brucellosis preventive behaviors among traditional ranchers in rural areas of Hamadan Province. J Educ Community Health. 2017;3(4):16-23. doi:10.21859/jech.3.4.16

16. Bennett JE, Dolin R, Blaser MJ. Mandell, Douglas, and Bennett's Principles and Practice of Infectious Diseases. 2 ed. Set: Elsevier Health Sciences; 2014.

17. Mirnejad R, Vafaei S. Antibiotic resistance patterns and the prevalence of ESBLs among strains of Acinetobacter baumannii isolated from clinical specimens. J Genes Microbes Immun. 2013;2013:1-8. doi:10.5899/2013/jgmi-00002

18. Babazadeh T, Nadrian H, Banayejeddi M, Rezapour B. Determinants of skin cancer preventive behaviors among rural farmers in Iran: an application of protection motivation theory. J Cancer Educ. 2017;32 (3):604-612. doi:10.1007/s13187-016-1004-7

19. Haghighi M, Taghdisi MH, Nadrian H, Moghaddam HR, Mahmoodi $\mathrm{H}$, Alimohammadi I. Safety culture promotion intervention program (SCPIP) in an oil refinery factory: an integrated application of geller and health belief models. Saf Sci. 2017;93:76-85. doi:10.1016/j. ssci.2016.11.019

20. Ramezankhani A, Jahani H, Hatami H, SHARIFZADEH G, HOSSEINI S. Determine the Effect of Intervention on the Adoption of Preventive Behaviours of the Brucellosis Was Based on the Health Belief Model. 2016.

21. McDermott J, Grace D, Zinsstag J. Economics of brucellosis impact and control in low-income countries. Rev Sci Tech. 2013;32(1):249261. doi:10.20506/rst.32.1.2197

22. Hotez PJ, Bottazzi ME, Franco-Paredes C, Ault SK, Periago MR. The neglected tropical diseases of Latin America and the Caribbean: a review of disease burden and distribution and a roadmap for control and elimination. PLoS Negl Trop Dis. 2008;2(9). doi:10.1371/journal. pntd. 0000300

23. Tabasi Nejad N, Mohseni M, Khanjani N, Ahmadi Tabatabaei S. Application of the PRECEDE-PROCEED model in promoting physical activity for prevention of osteoporosis among women. Health Educ Health Promotion. 2018;6(3):103-108. doi:10.29252/HEHP.6.3.103
24. Noviana C, Wibawan I, Sudarnika E. Knowledge, attitude, and practises of breeding kennel owner regarding canine brucellosis prevention and controlling on imported dogs. J Veteriner. 2016;17(2):265273. doi:10.19087/jveteriner.2016.17.2.265

25. Binkley CJ, Johnson KW. Application of the PRECEDE-PROCEED planning model in designing an oral health strategy. $J$ Theory Pract Dent Public Health. 2013;1(3).

26. Sharifi H, Abbasi M, Eybpoosh S, Akbarein H. Risk factors of human brucellosis in the Northeast of Iran. J Med Microbiol Infect Dis. 2016;4(1):20-24.

27. Smith JA, Shinebourne P. Interpretative Phenomenological Analysis. American Psychological Association; 2012.

28. Lawshe $\mathrm{CH}$. A quantitative approach to content validity 1. Pers Psychol. 1975;28(4):563-575. doi:10.1111/j.1744-6570.1975.tb01393.x

29. Henry JW, Stone RW. A structural equation model of end-user satisfaction with a computer-based medical information system. Inf Res Manage J. 1994;7(3):21-33. doi:10.4018/irmj.1994070102

30. Lomax RG, Schumacker RE. A Beginner's Guide to Structural Equation Modeling. psychology press; 2004.

31. Kline R. Details of Path Analysis. Principles and Practice of Structural Equation Modeling. New York: Guilford Press; 2005:123-164.

32. Schreiber JB, Nora A, Stage FK, Barlow EA, King J. Reporting structural equation modeling and confirmatory factor analysis results: a review. $J$ Educ Res. 2006;99(6):323-338. doi:10.3200/ JOER.99.6.323-338

33. Jahangiry L, Nadrian H, Mahdavi B, Allahverdipour H, Kousha A. Primary Development and psychometric properties of PRECEDE model-based scales for brucellosis prevention among an Iranian rural population. Arch Clin Infect Dis. 2017;12(3). doi:10.5812/ archcid. 62957

34. Ahmadzadeh M. Development and psychometric evaluation of the treatment adherence questionnaire for patients with combat posttraumatic stress disorder. Patient Prefer Adherence. 2019;13:419430. doi:10.2147/PPA.S175353

35. Polit DF, Beck CT. Nursing Research: Generating and Assessing Evidence for Nursing Practice. Lippincott Williams \& Wilkins; 2008.

36. Ranjandish F, Mahmoodi H, Shaghaghi A. Psychometric responsiveness of the health-related quality of life questionnaire (HeartQoL-P) in the Iranian post-myocardial infarction patients. Health Qual Life Outcomes. 2019;17(1):10. doi:10.1186/s12955-018-1075-8

37. Gorzka R-J, Rebling K, Höllmer H, et al. Psychometric evaluation of the Hamburg Nightmare Questionnaire (HNQ). Eur J Psychotraumatol. 2019;10(1):1592393. doi:10.1080/20008198.2019.1592393

38. Yari A, Nadrian H, Rashidian H, et al. Psychometric properties of the persian version of social capital questionnaire in Iran. Med $J$ Islam Repub Iran. 2014;28:17.

39. Rohani H, Eslami AA, Ghaderi A, et al. Validation and psychometric evaluation of physical activity belief scale among patients with type 2 diabetes mellitus: an application of health action process approach. Health Promotion Perspect. 2016;6(2):71. doi:10.15171/hpp.2016.13

40. Nadrian H, Nedjat S, Taghdisi MH, Shojaeizadeh D. Urban trafficrelated determinants of health questionnaire (UTDHQ): an instrument developed for health impact assessments. Med J Islam Repub Iran. 2014;28:84. 


\section{Publish your work in this journal}

Risk Management and Healthcare Policy is an international, peerreviewed, open access journal focusing on all aspects of public health, policy, and preventative measures to promote good health and improve morbidity and mortality in the population. The journal welcomes submitted papers covering original research, basic science, clinical \& epidemiological studies, reviews and evaluations, guidelines, expert opinion and commentary, case reports and extended reports. The manuscript management system is completely online and includes a very quick and fair peer-review system, which is all easy to use. Visit http://www.dovepress.com/testimonials.php to read real quotes from published authors.

Submit your manuscript here: https://www.dovepress.com/risk-management-and-healthcare-policy-journal 